\title{
Estudo da Cinética de Desinfecção de Águas Poluídas
}

\author{
Marta H. de Oliveira Felipe T. Barbosa* \\ Faculdade de Matemática, FAMAT, UFU, \\ 38700-126, Campus Patos de Minas, Patos de Minas, MG \\ E-mail: marta@famat.ufu.br, fernandesfelipe13@hotmail.com.
}

\section{RESUMO}

A água é um recurso natural essencial ao planeta e à preservação da vida de seus habitantes. A desinfecção é um tratamento responsável por livrar esse fluido de patógenos e substâncias indesejáveis ao seu consumo. O objetivo desse trabalho é, através de uma equação diferencial ordinária, estudar a cinética da desinfecção de águas poluídas.[1] A lei de Hom, 1972, relaciona a variação da população de bactérias $N$ em água com determinada concentração de desinfetante $C$ em relação ao tempo $t$.[3] A lei de Hom é descrita na equação 1, onde $k_{1}$ é a constante de decaimento do processo, $m$ e $n$ são constantes associadas a esse fenômeno e $N_{0}$ representa o número de bactérias presentes no instante zero.

$$
\left\{\begin{array}{l}
\frac{d N}{d t}=-k_{1} C^{n} t^{m-1} N \\
N(0)=N_{0}
\end{array}\right.
$$

A solução particular do problema de valor inicial 1 é dada por $N(t)=N_{0} e^{-k C^{n} t^{m}}$, onde $k=k_{1} / m$. A constante $k$ e os coeficientes $n$ e $m$ são obtidos por regressão linear múltipla e para isto é preciso linearizar a equação solução do problema de valor inicial.[2] A equação linearizada se reescreve da forma $\ln \left(-\ln \left(\frac{N}{N_{0}}\right)\right)=\ln k+n \ln C+m \ln t$, ou seja, $Y=\ln (k)+n X_{1}+m X_{2}$. Os dados utilizados neste trabalho estão apresentados na tabela 1 e referem-se à experimentos de desinfecção de água com cistos da bactéria Naegleria gruberi, com pH 5, sob a aplicação de cloro residual em diferentes concentrações e o tempo $t$ é medido em minutos.[3]

Para a regressão linear múltipla considera-se o método dos mínimos quadrados, cuja matriz dos coeficientes $X$ é composta por 52 linhas e 3 colunas. A matriz $X$ é constituída, em suas colunas, pelos vetores 1 na primeira, $\ln C$ na segunda e $\ln t$ na terceira, referente às constantes $\ln k, n$ e $m$, respectivamente. Nesta regressão foram desconsiderados todos os valores da tabela $1 \mathrm{em}$ que seria preciso o cálculo de $\ln (0)$, para a determinação do vetor $Y$. A equação matricial, da regressão múltipla, que obtém as constantes é dada por:

$$
v_{3 \times 1}=\left(X_{3 \times 52}^{t} * X_{52 \times 3}\right)^{-1} * X_{3 \times 52}^{t} * Y_{52 \times 1} .
$$

As constantes do modelo de Hom para esses dados são: $k=0.0792396, n=1.9828452 \mathrm{e}$ $m=1.9964747$. A comparação dos resultados analíticos com os resultados experimentais está ilustrada na figura 1. Conclui-se que a lei de Hom conseguiu representar a inativação da bactéria Naegleria gruberi.

Agradecimentos: Os autores, Marta e Felipe, agradecem a FAPEMIG, a FAMAT e a Profa. Dra. Fabrícia de Matos Oliveira pelo apoio.

Palavras-chave: Lei de Hom, modelo analítico, desinfecção de águas, edo de primeira ordem.

*aluno de Iniciação Científica PIVIC/FAPEMIG. 
Tabela 1: Desinfecção de água com Naegleria gruberi, com pH 5.

\begin{tabular}{c|c|c|c|c|c}
\hline \multirow{2}{*}{$\begin{array}{c}\text { Tempo de } \\
\text { contato (min) }\end{array}$} & \multicolumn{5}{|c}{ Cloro residual livre $(\mathrm{mg} / \mathrm{L})$} \\
\cline { 2 - 6 } & 0.45 & 0.57 & \multicolumn{6}{c}{0.9} & 2.12 & 2.64 \\
\hline 0 & 0 & 0 & 0 & 0 & 0 \\
\hline 0.5 & 0 & 0 & 0 & -0.115 & -0.230 \\
\hline 1 & 0 & 0 & -0.115 & -0.230 & -0.576 \\
\hline 1.5 & 0 & 0 & -0.230 & -0.345 & -1.612 \\
\hline 2 & 0 & 0 & -0.276 & -0.806 & -2.763 \\
\hline 2.5 & 0 & 0 & -0.345 & -1.612 & -2.763 \\
\hline 3 & -0.115 & -0.115 & -0.576 & -2.878 & -5.526 \\
\hline 4 & -0.230 & -0.345 & -1.151 & -4.605 & $\cdots$ \\
\hline 5 & -0.345 & -0.576 & -1.842 & $\cdots$ & $\cdots$ \\
\hline 6 & -0.576 & -0.921 & -2.533 & $\cdots$ & $\cdots$ \\
\hline 7 & -0.691 & -1.266 & -3.454 & $\cdots$ & $\cdots$ \\
\hline 8 & -0.921 & -1.382 & -4.605 & $\cdots$ & $\cdots$ \\
\hline 9 & -1.266 & -2.303 & -6.677 & $\cdots$ & $\cdots$ \\
\hline 10 & -1.612 & -2.993 & $\cdots$ & $\cdots$ & $\cdots$ \\
\hline 11 & -2.072 & -3.454 & $\cdots$ & $\cdots$ & $\cdots$ \\
\hline 12 & -2.533 & -3.914 & $\cdots$ & $\cdots$ & $\cdots$ \\
\hline 13 & -2.993 & -4.605 & $\cdots$ & $\cdots$ & $\cdots$ \\
\hline 14 & -3.569 & -5.296 & $\cdots$ & $\cdots$ & $\cdots$ \\
\hline 15 & -3.814 & -5.756 & $\cdots$ & $\cdots$ & $\cdots$ \\
\hline 16 & -4.720 & -6.562 & $\cdots$ & $\cdots$ & $\cdots$ \\
\hline
\end{tabular}

Fonte: Daniel (2001, p. 92).

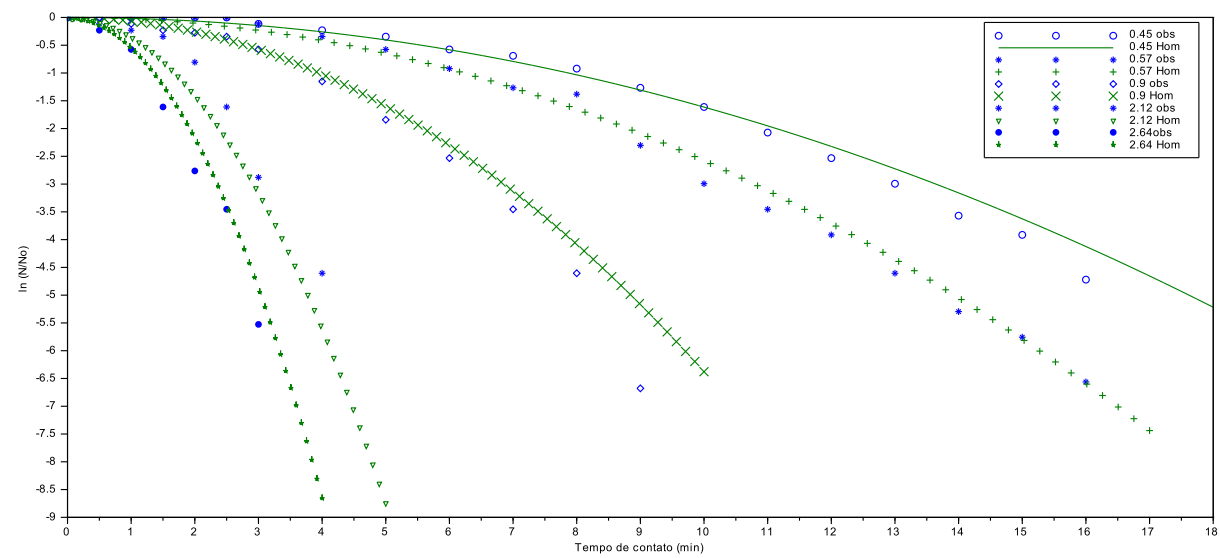

Figura 1: Comparação dos resultados experimentais com o modelo de Hom.

\section{Referências}

[1] W. E. Boyce e R. C. DiPrima, "Equações diferenciais elementares e problemas de valores de contorno", 9a ed., Editora LTC, Rio de Janeiro, 2012.

[2] R. Charnet, H. Bonvino, C. A. L. Freire e E. M. R. Charnet, "Análise de modelos de regressão linear: Com aplicações", Editora Unicamp, Campinas, 2008.

[3] L. A. Daniel, "Métodos alternativos de desinfecção da água", PROSAB, Rima Editora, São Carlos, 2001. 